\title{
ROLE OF HYPERBARIC OXYGEN IN NEO-OSTEOGENESIS IN FRACTURES OF LONG BONES
}

\author{
Jiss Joseph Panakkal1, Vijoy Kumar Sinha V. S. M² $^{2}$ \\ 1 Assistant Professor, Department of Orthopaedics, SNIMS, Ernakulam, Kerala, India. \\ 2Formerly Sr. Advisor and Professor, Department of Orthopaedics, INHS Asvini, Colaba, Mumbai, Maharashtra, India.
}

\section{BACKGROUND}

ABSTRACT

Hyperbaric Oxygen Therapy (HBOT) has been proved to regenerate and revitalize various tissues of the body. But, the role of HBOT in promoting neo-osteogenesis has been experimented mainly in animals. Clinical evidence to support or negate its effectiveness in humans for neo-osteogenesis is lacking due to non-availability of good quality trials. We wanted to assess the role of hyperbaric oxygen in neo-osteogenesis of the fractures of long bones.

\section{MATERIALS AND METHODS}

A randomised control trial was conducted in the Department of Orthopaedics in Indian Naval Hospital Ship Asvini from July 2006 to Mar. 2009. Patients requiring abundant callus for healing like comminuted fractures of long bones, treated by relative stability, fixation and those requiring bone transport, managed with the Ilizarov ring fixator are included in the study. 70 patients who met the selection criteria were randomly allotted to 2 groups with 35 patients each. Patients treated with no HBOT (n=29) as control group (Group 1) and patients treated with HBOT (n=34) as study group (Group 2) as 6 patients from control group and 1 patient from study group were lost to follow-up. Cases selected for trial were given HBOT with 100\% oxygen for 45 minutes in a recompression chamber at 2 ATA for 3 weeks. The assessment of osteogenesis was done clinically, radiologically and sonologically at 3 weeks, 6 weeks, 12 weeks and thereafter 6 weekly, till fracture union.

\section{RESULTS}

At 3 weeks, sonological evidence of neo-osteogenesis was found in 55.9\% of study group and $44.8 \%$ of control group. A similar result of clinical and early radiological evidence was noticed at 6 weeks of follow up. However, there was no significant difference in the neo-osteogenesis noticed between case and control group in the further follow up.

\section{CONCLUSION}

Our study failed to show any significant clinical evidence to support or refute the effectiveness of HBOT for the union of fractures. A clinical trial with large sample size is needed to define the role of HBOT in fracture healing, if any.

\section{KEY WORDS}

Fracture Healing, Hyperbaric Oxygen, Fractures of Long Bones, Neo-Osteogenesis

HOW TO CITE THIS ARTICLE: Panakkal JJ, Sinha VKVSM. Role of hyperbaric oxygen in neo-osteogenesis in fractures of long bones. J. Evolution Med. Dent. Sci. 2019;8(11):793-796, DOI: 10.14260/jemds/2019/174

\section{BACKGROUND}

Fracture healing occurs in most patients with fractures of long bones irrespective of the treatment. However, $10 \%$ of fractures can have some degree of impaired healing leading to delayed union and non-union.(1) Hence any intervention that can hasten the process of neo-osteogenesis is of great medical and socio-economic importance.

Administration of $100 \%$ oxygen at pressures greater than one atmosphere (ATA) in a closed chamber is called Hyperbaric oxygen therapy (HBOT). HBOT has been proved to be of great value in regeneration and revitalization of various tissues of the body.

Despite the benefit of HBOT for delayed bone healing and non-union of bony fractures has been proposed since 1966,(2) little has been known about its effect on osteoblasts and bone marrow stem cells.

'Financial or Other Competing Interest': None.

Submission 24-10-2018, Peer Review 25-12-2018,

Acceptance 31-12-2018, Published 11-03-2019.

Corresponding Author:

Jiss Joseph Panakkal,

Panakkal House, N Kuthiathode P. O.,

Kankkankadavu, Ernakulam District-683594,

Kerala, India.

E-mail: jissjoseph@hotmail.com

DOI: 10.14260/jemds/2019/174
Bone healing involves intricate pathophysiologic processes. It has been found that decreased NO production, infection, and hypoxia inhibit the healing process.(3),(4) Reduced neurogenic vascular response, impaired cutaneous vasodilation and endothelial cell dysfunction are correlated with reduced NO production.(3) Although hypoxia initiates healing through regulation of macrophage angiogenesis factor, the oxygen dependent cellular repair processes can be impaired.(4) Studies have shown that HBOT enhances collagen synthesis in tissue and fibroblast replication.(5) It also helps in angiogenesis.(6-8) osteoclastic and osteoblastic activity ${ }^{(9-11)}$ and positively affects NO production(3) by increasing endothelial nitric oxide synthase.(12)

Unfortunately, the role of HBOT in promoting neoosteogenesis has been experimented mainly in animals. Ueng et al,(9) in 1998 investigated the effect of HBOT on bone healing in rabbits and found that the torsional strength of lengthened tibia of HBOT group was increased significantly. Another study by Demirtas et al,(13) in 2014 found that the negative effects of nicotine on fracture healing in nicotinised rats are eliminated with hyperbaric oxygen therapy.

An in vitro study of HBOT on the proliferation and differentiation of human osteoblasts derived from alveolar bone was analysed at the Institute of Health and Biomedical Innovation, Queensland University of Technology, Brisbane, 
Australia.(14) HBOT found to enhance biomineralization, bone nodule formation and alkaline phosphatase activity.(14)

A systematic review of human clinical trials of HBOT done by Bennet et al(15) in 2004 failed to identify any relevant clinical evidence due to lack of good quality trials.

Assessing the regenerate in osteogenesis is crucial for clinical treatment. Several methods have been used to evaluate this, including digital radiography,(16) quantitative computed tomography, dual energy x-ray absorptiometry, and ultrasound. The lack of radiation with sonography makes it a preferable non-invasive predictor of bone regenerate than radiographs. There is a direct correlation between the morphologic development visible on ultrasound and the stage of the callus formation.(17-19)

\section{Aim of The Study}

To assess the role of hyperbaric oxygen in neo-osteogenesis of the fractures of long bones.

\section{MATERIALS AND METHODS}

A randomised control trial was conducted in the Department of Orthopaedics in INHS Asvini from July 2006 to Mar 2009. Patients requiring exuberant callus for healing like comminuted fractures of long bones, treated by relative stability fixation using nails or plates and those requiring bone transport, managed with the Ilizarov ring fixator were included in the study. Patients with pathological fractures, multiple injuries and those who fail to follow up were excluded. X-Ray chest, ECG and ENT examinations were done before starting HBOT to rule out pulmonary pathology, cardiac arrhythmias and to ensure eustachian tube patency before commencing HBOT.

70 patients who met the selection criteria were randomly allotted to 2 groups with 35 patients each using blocked randomisation.

The sample size calculation: This is a pilot study, as there is no available similar studies in the past. Based on the previous hospital data, the number of long bone fractures expected to avail treatment in the hospital during the stipulated period is around 75 . Adding $5 \%$ for attrition during follow up, the overall sample size of the study decided to be 70 .

Randomisation: Block randomization was used to allocate participants into the two RCT groups. As all the participants received the same onsite interventions, block randomization of each participant after enrolment was feasible. One of the authors who did not participate in the subject recruitment generated random permutations of the two RCT arms within each block, using the web site http://www.random.org (a web site for generating random integers) to ensure that the size of the two groups was similar, Then, the investigator allocated the random permutations of treatments to the list of the participants. Recruitment staff was blinded from the allocation of participants.

Group I- Patients treated with no HBOT as control group. Group II- Patients treated with HBOT as study group.
Pre-operative assessment and planning was done in each case with the help of X-rays. All fractures were categorised according to the union potential grading suggested by Bhargava et al.(20)

Cases selected for trial were given HBOT with $100 \%$ oxygen for 45 minutes in a recompression chamber at 2 ATA for 3 weeks. RCC used in our hospital is a type X-22H chamber manufactured by Comex Industries, USA.

The assessment of osteogenesis was done clinically, radiologically and sonologically at 3 weeks, 6 weeks, 12 weeks and thereafter every six weeks till fracture union. Sonographic evaluation was carried out using an $11 \mathrm{MHz}$ transducer. We used the Union Scale Score proposed by Bhargava et al(20) to reduce subjective bias in assessing bone union. This numerical score has three criteria, namely fracture site mobility, tenderness and radiological features. A score of six or more was taken as sound union.

Statistical Methods: SPSS version 20 was used for statistical analysis. All study variables were represented using frequency and percentage. Chi-square test / Fisher's exact test was performed to compare the study variables between control and study groups. The p-value less than 0.05 would be taken as statistically significant.

\section{RESULTS}

There were 29 patients in control group and 34 patients in study group as 6 patients from control group and 1 patient from study group failed to follow up. Clinically, the duration of union was less than 6 weeks in $55.6 \%$ cases, $6-12$ weeks in $33.3 \%$ cases and more than 12 weeks in $3.2 \%$ weeks. Around $7.9 \%$ cases with no union were also noted. Almost similar distribution of duration was noted in both case and control groups. Radiologically, the duration of union was less than 6 weeks in $50.8 \%$ cases, $6-12$ weeks in $36.5 \%$ cases and more than 12 weeks in $3.2 \%$ weeks. Around 9.5\% cases with no union were also noted. Almost similar distribution of duration was noted in both case and control groups. Sonologically, the duration of union was less than 3 weeks in $50.8 \%$ cases, $3-6$ weeks in $33.3 \%$ cases and more than 6 weeks in $6.3 \%$ weeks. Around $9.5 \%$ cases with no union were also noted. Almost similar distribution of duration was noted in both case and control groups.

\section{Comparison of Union Potential Score Between Case and Control}

There is no difference in union potential score between case and control. The table reveals that the good union potential score is almost same in case (85.3\%) and control (75.9\%) groups. No difference in union potential score was noted in any type of fractures (as the p-value is greater than the significance level 0.05).

\section{Comparison of Union Scale Score Between Case and Control}

There is no difference in union scale score between case and control. The table reveals that the united cases are almost same in case $(94.1 \%)$ and control $(86.2 \%)$ groups. No difference in union was noted in any type of fractures (as the $\mathrm{p}$-value is greater than the significance level 0.05). 


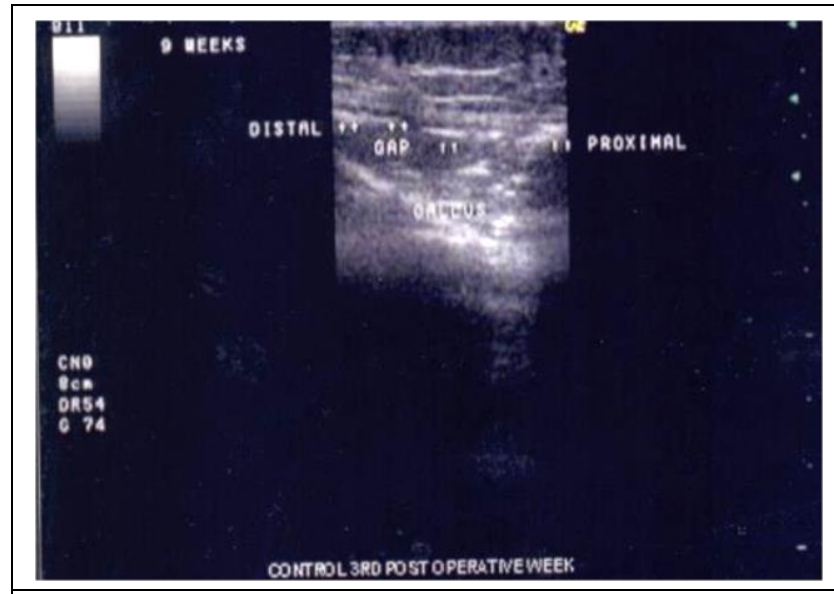

Figure 1. Control: USGM $3^{\text {rd }}$ Week Post Op of Corticotomy Site Showing Emergence of Echogenic Foci in The Regenerate

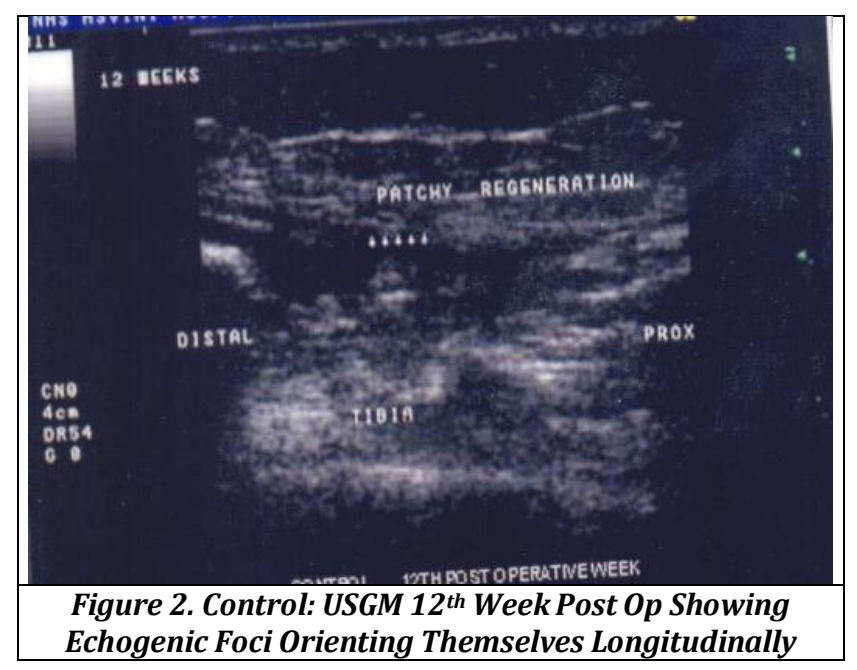

\section{DISCUSSION}

In our study, the cases which showed earlier osteogenesis went on to earlier consolidation. Echogenic foci in distraction gap were found as early as 20.7 days after start of distraction, whereas radiographic signs were seen at an average of 48.3 days. With further distraction it was found that the echogenic foci aligned themselves longitudinally. Bone mineralization increased rapidly once the distraction was stopped. The sonograms showed a hyper reflecting solid line. Once cortical bone formation started, after which further sonological assessment was difficult.

The advantage of ultrasound for the early detection of callus formation has been confirmed by Richter D and Hahn MP in their study published in 1996.(21) In their study of 24 patients with long-bone fractures, Maffulli $\mathrm{N}$ and Thornton also got similar results.(17) The clinical relevance is that an earlier diagnosis of a healing fracture could allow early mobilization and weight bearing. Exact quantification by CT scan and DEXA studies are precluded due to exposure of radiation. Hence, for fracture healing evaluation, we chose ultra sound along with X-ray and got similar results.

All fractures in the study were assessed using union potential score proposed by Bhargava et al(20). The fracture union depends on various factors and this score takes into account, the common factors which can affect the union. This preoperative scoring helps to predict the fracture union.
To avoid the subjective bias of assessment, the fracture union was assessed by union scale score proposed by Bhargav et al,(20) which is a numerical score to assess the progress of union. The score has three criteria, namely fracture site mobility, tenderness and radiological features, however as all fractures in our study were fixed by internal or external fixation, mobility could not be assessed.

The lack of randomised trials to support or refute the treatment of acute or non-united fractures with hyperbaric oxygen therapy has made it difficult to utilise the full potential of HBOT. The only randomised clinical trial which was found to be significant by Bennet et al in his metanalysis is the trial done by Lindstrom et al.(22) $\mathrm{He}$ analysed distal blood flow of 20 cases of intramedullary nailing of tibial shaft fractures and reported some improvement in the blood flow with HBOT. However, the effect of fracture healing was not analysed.

Our study fulfilled most of the criteria proposed by Bennet et al(15) like careful definition and selection of target patients, appropriate oxygen dosage and appropriate outcome measures. We found early neo- osteogenesis in patients with HBOT, but the study did not have adequate sample size to detect the expected minor difference. Hence, any significant clinical evidence to support or refute the effectiveness of HBOT for the union of fractures cannot be made.

\section{CONCLUSION}

This study failed to show any relevant clinical evidence to support or refute the effectiveness of HBOT for the union of fractures. Further trials with adequate sample size are needed to define the role, if any, of HBOT in the treatment of these injuries to draw a meaningful valid conclusion.

\section{REFERENCES}

[1] Einhorn TA. Enhancement of fracture-healing. J Bone Joint Surg Am 1995;77(6):940-56.

[2] Coulson DB, Ferguson AB Jr, Diehl RC Jr. Effect of hyperbaric oxygen on the healing femur of the rat. Surg Forum 1966;17:449-50.

[3] Boykin JV Jr. The nitric oxide connection: hyperbaric oxygen therapy, becaplermin and diabetic ulcer management. Adv Skin Wound Care 2000;13(4 Pt 1):169-74.

[4] Knighton DR, Hunt TK, Scheuenstuhl H, et al. Oxygen tension regulates the expression of angiogenesis factor by macrophages. Science 1983;221(4617):1283-5.

[5] Siddiqui A, Galiano RD, Connors D, et al. Differential effects of oxygen on human dermal fibroblasts: acute versus chronic hypoxia. Wound Repair Regen 1996;4(2):211-8.

[6] Tompach PC, Lew D, Stoll JL. Cell response to hyperbaric oxygen treatment. Int J Oral Maxillofac Surg 1997;26(2):82-6.

[7] Marx RE, Johnson RP, Kline SN. Prevention of osteoradionecrosis: a randomized prospective clinical trial of hyperbaric oxygen versus penicillin. J Am Dent Assoc 1985;111(1):49-54. 
[8] Zhao LL, Davidson JD, Wee SC, et al. Effect of hyperbaric oxygen and growth factors on rabbit ear ischemic ulcers. Arch Surg 1994;129(10):1043-9.

[9] Ueng SW, Lee SS, Lin SS, et al. Bone healing of tibial lengthening is enhanced by hyperbaric oxygen therapy: a study of bone mineral density and torsional strength on rabbits. J Trauma \& Acute Care Surgery 1998;44(4):676-81.

[10] Buras JA, Stahl GL, Svoboda KK, et al. Hyperbaric oxygen downregulates ICAM-1 expression induced by hypoxia and hypoglycemia: the role of NOS. Am J Physiol Cell Physiol 2000;278(2):C292-302.

[11] Schaffer MR, Tantry U, Gross SS, et al. Nitric oxide regulates wound healing. J Surg Res 1996;63(1):23740.

[12] Bruch-Gerharz D, Ruzicka T, Kolb-Bachofen V. Nitric oxide in human skin: current status and future prospects. J Invest Dermatol 1998;110(1):1-7.

[13] Demirtas A, Azboy I, Bulut M, et al. The effect of hyperbaric oxygen therapy on fracture healing in nicotinized rats. Ulus Travma Acil Cerrahi Derg 2014;20(3):161-6.

[14] Wu D, Malda J, Crawford R, et al. Effects of hyperbaric oxygen on proliferation and differentiation of osteoblasts from human alveolar bone. Connect Tissue Res 2007;48(4):206-13.

[15] Bennett MH, Stanford R, Turner R. Hyperbaric oxygen therapy for promoting fracture healing and treating fracture non-union. Cochrane Database Syst Rev 2005;(1):CD004712.
[16] Kolbeck S, Bail H, Weiler A, et al. Digital radiography. A predictor of regenerate bone stiffness in distraction osteogenesis. Clin Orthop Relat Res 1999;(366):221-8.

[17] Maffulli N, Thornton A. Ultrasonographic appearance of external callus in long-bone fractures. Injury 1995;26(1):5-12.

[18] Ricciardi L, Perissinotto A, Dabala M. External callus development on ultrasound and its mechanical correlation. Ital J Orthop Traumatol 1992;18(2):223-9.

[19] Ricciardi L, Perissinotto A, Visentin E. Ultrasonography in the evaluation of osteogenesis in fractures treated with Hoffmann external fixation. Ital J Orthop Traumatol 1986;12(2):185-9.

[20] Bhargava R, Sankhla SS, Gupta A, et al. Percutaneous autologus bone marrow injection in the treatment of delayed or nonunion. Indian J Orthop 2007;41(1):6771.

[21] Richter D, Hahn MP, Ostermann PA, et al. Ultrasound follow-up of callus distraction--an alternative to roentgen diagnosis? Langenbecks Arch Chir Suppl Kongressbd 1996;113:931-3.

[22] Lindstrom T, Gullichsen E, Lertola K, et al. Effects of hyperbaric oxygen therapy on perfusion parameters and transcutaneous oxygen measurements in patients with intramedullary nailed tibial shaft fractures. Undersea Hyperb Med 1998;25(2):87-91. 